\title{
Evidence for Long-term Cross-Language Repetition Priming in Conceptual Implicit Memory Tasks
}

\author{
René Zeelenberg \\ Indiana University and University of Amsterdam \\ Diane Pecher \\ Utrecht University
}

\begin{abstract}
Previous studies have failed to find evidence for longterm cross-language repetition priming (e.g., presentation of the English word frog does not facilitate responding to its Dutch translation equivalent kikker on a later presentation). The present study tested the hypothesis that failure to find cross-language repetition priming in previous studies was due to the use of tasks that rely primarily on lexical or orthographic processing of the stimuli instead of conceptual processing. Consistent with this hypothesis we obtained reliable cross-language repetition priming when conceptual implicit memory tasks were used. The present results support theories of bilingual memory that assume shared conceptual representations for translation equivalents.
\end{abstract}

Key Words: bilingual memory, conceptual memory, long-term priming, repetition priming, cross-language priming, language independence

It is estimated that the majority of the people in the world are bilingual. It is not surprising therefore that many researchers have become interested in how language is represented and processed in people who master more than one language. A question that has received considerable attention in the literature is whether the two languages of a bilingual person have separate or shared (also called integrated) representations. Initially researchers assumed separate representations for translation equivalents (e.g., Kolers, 1963). Many current theories of bilingual processing and memory representation, however, assume that representations of translation equivalents are integrated to some degree (e.g., Kroll \& Stewart, 1994; Potter, So, Von Eckhart, \& Feldman, 1984). A number of findings have been taken to support this view. For example, semantic priming effects are obtained even when the prime and target words are presented in different languages (e.g., Kirsner, Smith, Lockhart, King, \& Jain, 1984; de Groot \& Nas, 1991). Additionally, Stroop interference is obtained when ink colors must be named in a language different from the one in which the words are printed (see MacLeod, 1991, for a review). Also, in a category-verification task, reaction times are as fast when the category and its member are presented in the same language as when they are presented in different languages (e.g., Caramazza \& Brones, 1980). These and other findings are consistent with the notion of shared bilingual memory representations (see Francis, 1999, for a review).

Results obtained with the long-term repetition priming paradigm, however, have provided little evidence for shared representations. ${ }^{1}$ Repetition priming refers to the common finding, well documented in the monolingual memory and language literature, that participants respond faster and more accurate to recently studied words than to words that have not been studied recently (e.g., Jacoby \& Dallas, 1981; Scarborough, Cortese, \& Scarborough, 1977; Zeelenberg, Wagenmakers, \& Raaijmakers, 2002). The question is whether repetition priming is also obtained when the first and second presentation of a word in the experiment are in a different language (e.g., does the previous presentation of the English word frog facilitate responding to its Dutch translation equivalent kikker?). A number of experiments using the lexical decision task indicate that no such effect is obtained (Gerard, \& Scarborough, 1989; Kirsner, Brown, Abrol, Chadna, \& Sharma, 1980; Kirsner, et al., 1984; Scarborough, Gerard, $\&$ Cortese, 1984) when the translation equivalents are noncognates (i.e., when they are orthographically and phonologically dissimilar). The absence of crosslanguage repetition priming seems to be inconsistent with the idea of shared representations.

Several researchers (for recent reviews see, de Groot, in press; Gollan \& Kroll, 2001) have argued, however, that cross-language repetition priming is not obtained in lexical decision because performance in lexical decision depends primarily on orthographic or lexical processes. In accordance with many current theories of monolingual and bilingual language processing, these researchers distinguish between a lexical and a conceptual level of representation. It is often assumed that the lexical level represents the orthography of a word whereas the semantic or conceptual level represents the meaning of a word. Most current theories of bilingual memory representation assume separate or language specific representations for translation equivalents at the lexical level of representation and shared or integrated representations at the conceptual level of representation. 
Because these theories assume separate lexical representations for translation equivalents they predict no cross-language repetition priming for tasks that tap lexical processes.

A closely related explanation for the absence of cross-language repetition priming in lexical decision is provided by the transfer appropriate processing (TAP) framework (Blaxton, 1989; Morris, Bransford \& Franks, 1977; Roediger, 1990; Roediger \& Blaxton, 1987). The TAP framework accounts for a number of findings in the implicit memory literature (see Roediger \& McDermott, 1993, for a review). According to the TAP framework, memory performance and hence priming, depends on the extent to which the processes at retrieval recapitulate the processes at encoding. Within the TAP framework a distinction is often made between perceptual and conceptual memory tasks. Performance in perceptual tasks relies primarily on the processing of the physical attributes of the presented stimuli whereas performance in conceptual tasks relies primarily on the processing of the semantic attributes of the presented stimuli. Crosslanguage repetition priming is not found in tasks that emphasize perceptual processes, because there is little or no overlap in the perceptual processes at study and test.

The interpretation that priming in lexical decision depends primarily on perceptual, orthographic or lexical processes and not conceptual processes is consistent with the ideas of many researchers in the field of monolingual repetition priming (e.g., Bowers, 2000; Becker, Moscovitch, Behrmann, \& Joordens, 1997; Zeelenberg \& Pecher, 2002). It should be noted, however, that the evidence supporting the hypothesis that crosslanguage repetition priming is not obtained in lexical decision because priming depends on lower level formbased processing is circumstantial. There is no direct evidence supporting this hypothesis. The aim of the present study was to provide a more direct test of this hypothesis.

A prediction that follows from the reasoning outlined above is that cross-language repetition priming should be obtained in implicit memory tasks that rely on conceptual processing. Some support for this idea was obtained by Durgunoglu and Roediger (1987). They used the TAP perspective to account for the fact that in some memory tasks cross-language transfer is observed while in other tasks no such transfer is observed. They predicted that evidence for cross-language transfer would be found in tasks that emphasize conceptual processing, but not in tasks that emphasize perceptual processing. In agreement with this prediction, their results showed that in free recall, a conceptually driven task, language at study played little role. However, in word fragment completion, a data-driven task, language at study played a major role and performance was no better for words studied in a different language than for nonstudied words (i.e., there was no evidence for cross-language repetition priming).

The results of Durgunoglu and Roediger (1987) provide some support for the idea that cross-language repetition priming might be obtained in tasks that rely on conceptual processing. It should be noted though that the Durgunoglu and Roediger study provides no definitive evidence because word fragment completion and free recall not only differ in the extent to which they rely on perceptual versus conceptual processes. These tasks also differ in the sense that word fragment completion is an implicit memory task and free recall is an explicit memory task. Numerous studies have shown dissociations between implicit and explicit tasks even when only conceptual tasks are considered (e.g., Humphreys, Tehan, O'Shea, \& Boland, 2000; GoshenGottstein \& Kempinsky, 2001; Shimamura \& Squire, 1984; Weldon \& Coyote, 1996). Thus, an alternative interpretation of the Durgunoglu and Roediger results is that cross-language transfer is obtained in explicit tasks but not in implicit tasks. A more specific reason why cross-language transfer might be obtained in explicit tasks but not in implicit tasks is that in explicit tasks memory performance might be influenced by translation strategies at test (see Francis, 1999, for a more elaborate discussion of translation strategies). Such strategies are less likely to occur in implicit memory tasks, because subjects are not tested for their memory, but are simply asked to perform a certain task (e.g., decide whether or not a string of letters forms an existing word or decide whether a word refers to something 'animate' or 'inanimate'). Thus, it remains to be shown that crosslanguage repetition priming effects occur in conceptual implicit memory tasks.

The large majority of studies investigating repetition priming have used tasks that rely primarily on perceptual or orthographic processes. ${ }^{2}$ Recently, however, priming in conceptual implicit memory tasks has gained more attention (e.g., Becker, et al., 1997; Mulligan \& Stone, 1999; Vriezen, Moscovitch, \& Bellos, 1995). Some examples of conceptual implicit memory tasks that have been used in previous studies are animacy decision, man-made decision, free association and categoryexemplar production. These conceptual implicit memory tasks, however, have been used almost uniquely in monolingual repetition priming studies. To our knowledge, the only experiment that investigated crosslanguage repetition priming in a conceptual implicit memory task (animacy decision) was performed by Kirsner et al. (1984, Experiment 3). Somewhat surprisingly, Kirsner et al. failed to find evidence for cross-language repetition priming. Thus, even in conceptual implicit memory tasks there is no evidence for cross-language repetition priming.

The absence of cross-language repetition priming in the Kirsner et al. (1984) study seems to suggest that the explanation that cross-language repetition priming in lexical decision is not obtained because priming in this task depends primarily on perceptual or orthographic processes and not conceptual processes might be incorrect. Given, however, that this is the only published experiment investigating cross-language repetition priming in a conceptual implicit memory task we wanted to take a further look at cross-language repetition priming in these tasks. More specifically, the present study investigated cross-language repetition priming in animacy 
decision and man-made decision, two semantic classification tasks. It is important to ensure that priming in semantic classification tasks is indeed due to conceptual processing, otherwise we might still fail to obtain evidence for cross-language repetition priming. A number of findings from the monolingual repetition priming literature indicate, however, that priming in semantic classification tasks indeed depends on conceptual processing and therefore these tasks are well suited to study cross-language repetition priming. These monolingual studies have shown that in semantic classification tasks: a) repetition of the lexical processing of an item produces little or no priming (Franks, Bilbrey, Lien, \& McNamara, 2000; Vriezen et al., 1995), b) priming is not affected by changes in modality of presentation (auditory vs. visual) from study to test (Thompson-Schill \& Gabrieli, 1999), and c) priming is affected by the extent to which there is an overlap in the type of conceptual processing at study and test (Huntjens et al., 2002; Vriezen et al., 1995; Thompson-Schill \& Gabrieli, 1999).

The latter point is of particular importance because it suggests that we may fail to obtain repetition priming if the study and test tasks emphasize different aspects of the conceptual knowledge of a word stored in memory. 3 Because research indicates that priming in semantic classification tasks depends largely on specific conceptual knowledge words in Experiment 1 were presented in an animacy decision task (i.e., participants judged words to be living or nonliving) during both study and test. In the same-language condition, the target words were presented in Dutch (the native language of our participants) during both study and test. In the cross-language condition, target words were presented in English during study and in Dutch during test. The question was whether cross-language repetition priming would be observed under these circumstances, as is predicted by theories that assume shared representations for translation equivalents at the conceptual level of representation.

\section{EXPERIMENT 1}

\section{Method}

Participants. Fifty-two Dutch university students participated for a small monetary reward. Twenty-six students were randomly assigned to the same-language repetition condition and the other 26 students were assigned to the cross-language repetition condition. None of the participants participated in more than one experiment of the present study.

Participants in all experiments of the present study consisted of students of the University of Amsterdam and Utrecht University. The participants were all native Dutch speakers for whom English was their second language (in some cases third language). As of 1993, all elementary schools in the Netherlands are required to teach English in grade 7 (around age 10) and 8. The vast majority of students have subsequently received 6 years of English teaching at secondary school. Thus, students typically have 8 years of formal training in English before entering the university. Participants in the present study frequently encounter English in their daily lives, as the majority of textbooks used at the university are written in English. In more informal settings students are also frequently exposed to English as a substantial part of movies and television programs in the Netherlands are in the English language (i.e., subtitles are used, foreign language productions are not dubbed). Students from similar populations of Dutch university students have been tested in several other bilingual studies (e.g., de Groot \& Nas, 1991; Kroll \& Stewart, 1994; La Heij, Hooglander, Kerling, \& van der Velden, 1996; van Hell \& de Groot, 1998; van Heuven, Dijkstra, \& Grainger, 1998).

Materials and design. Study status (studied vs. nonstudied) was manipulated within subjects and language condition (same-language vs. cross-language) was manipulated between subjects. In the same-language repetition condition, Dutch words were presented during the study phase and repeated in the test phase. In the cross-language repetition condition, English words (e.g., shark) were presented in the study phase and their Dutch translation equivalents (e.g., haai) were presented in the test phase. Repetition priming was assessed by comparing performance for studied words to performance for the nonstudied words.

The experimental stimuli consisted of 48 EnglishDutch noncognate translation pairs. Twenty-four pairs referred to living things (e.g., shark-haai, butterflyvlinder) and 24 pairs referred to nonliving things (mountain-berg, paint-verf). The mean cognate rating for the translation pairs was $1.29(S D=0.16)$ on a scale from 1 to 7 , with 1 meaning that the translation equivalents were very dissimilar and 7 meaning that the translation equivalents were very similar. ${ }^{4}$ Frequency counts were obtained from the CELEX norms (Baayen, Piepenbrock, \& Van Rijn, 1993). The median frequency per million was 30.5 (range 3.2 - 323.1) for the Dutch words and 41.8 (range 3.7 - 403.7) for their English translation equivalents. A complete listing of the experimental stimuli is provided in the Appendix.

A set of 48 translation pairs served as fillers in the study phase. In the cross-language condition the English words were presented as fillers and in the same-language condition the Dutch words were presented (i.e., word fillers were always presented in the same language as the experimental stimuli). An additional set of 24 Dutch words served as fillers in the test phase. Fillers were never repeated in the experiment. Four different study-test list combinations were generated for counterbalancing purposes. Across the four study-test list combinations each word appeared once in each of the four conditions (i.e., studied vs. unstudied crossed with cross-language vs. same-language).

Procedure. Participants received spoken and written instructions. They were instructed to make a 'living' decision if the word represented something living (i.e., a human being, animal or plant), or part of a living thing and to make a 'nonliving' decision if the word represented something not living. Examples of living and nonliving 
things were provided. The experiment consisted of a study block and a test block. In both blocks words were presented in an animacy decision task. Some of the words presented in the study block were repeated in the test block (either in the same or a different language). Participants were not informed about the relation between the study and test block.

Words were presented one at a time on a computer screen. Each trial started with the presentation of a fixation mark $(* * * * *)$ for $500 \mathrm{~ms}$. The fixation mark was followed immediately by the target stimulus that remained on the screen until the participant had made a response by pressing the ?/-key for 'living' response or z-key for 'nonliving' response. If the participant made an error the word 'FOUT' (error) was presented for $1000 \mathrm{~ms}$. If the response was correct but slower than $1200 \mathrm{~ms}$ the words 'TE LANGZAAM' (too slow) were presented for $1000 \mathrm{~ms}$. The next trial started $500 \mathrm{~ms}$ after the response or feedback.

The study block consisted of 72 trials and started with the presentation of 24 filler words to familiarize participants with the animacy decision task. Subsequently, 24 experimental stimuli and an additional 24 fillers were presented in a random order (in all experiments reported in this paper a different random order was used for each participant). The study block was followed by a test block consisting of 72 trials. Filler words were presented on the first 12 trials. Subsequently, 48 experimental stimuli and 12 additional fillers were presented in a random order. The 48 experimental stimuli consisted of 24 new words (i.e., words that had not been presented earlier in the experiment) and 24 old words (i.e., words that had been presented in the study phase, either in the same language or in a different language). Twelve of the 24 new words and 12 of the 24 old words referred to living things and the other 12 new words and 12 old words referred to nonliving things. Participants were allowed to take a short break between the study and test phase. In the cross-language condition, participants were informed about the change in language immediately before the start of the test phase.

\section{Results and discussion}

Mean reaction times for correct responses were calculated for each condition. Responses more than 2.5 standard deviations above or below each participant's mean were excluded from the analyses. The same outlier criterion was used in all subsequent experiments. Trimming resulted in removal of $3.7 \%$ of the reaction times The mean reaction times and percent errors are shown in Table 1. As can be seen we did obtain a crosslanguage repetition priming effect. A same-language repetition priming effect was also obtained.

These conclusions were supported by two-way ANOVAs on the reaction times and error rates with repetition condition (studied vs. nonstudied) as a withinsubjects condition and language condition (samelanguage vs. cross-language) as a between-subjects condition. The ANOVA on the mean reaction times showed that the main effect of repetition was significant, $F(1,50)=14.01, p<.001, M S E=912.6$. Neither the main effect of language condition, nor the interaction between repetition and language condition were significant, $F(1,50)<1, M S E=19907.6$, and $F(1,50)<1, M S E=912.6$, respectively. Most important, simple effects showed that the repetition priming effect was significant in both the same-language condition and the cross-language condition, $F(1,50)=9.14, p<.01, M S E=912.6$, and $F(1,50)=5.15, p<.05, M S E=912.6$, respectively.

Table 1

Mean Animacy Decision Times (in Milliseconds) and Percent Errors in Experiment 1

\begin{tabular}{lrc}
\hline Condition & RT & PE \\
& & \\
\hline Same-language & & \\
$\quad$ Studied & 647 & 4.2 \\
$\quad$ Nonstudied & 672 & 4.5 \\
Priming & 25 & 0.3 \\
& & \\
Cross-language & & \\
$\quad$ Studied & 653 & 4.8 \\
$\quad$ Nonstudied & 672 & 7.4 \\
$\quad$ Priming & 19 & 2.6 \\
&
\end{tabular}

The ANOVA on the error rates showed that the main effects of repetition and language condition were marginally significant, $F(1,50)=3.54, p=.07, M S E=$ 15.278 , and $F(1,50)=3.15, p=.08, M S E=25.640$, respectively. The interaction was not significant, $F(1,50)$ $=2.14, p>.10, M S E=15.278$. Simple effects showed that the repetition priming effect was not significant in the same-language condition, $F(1,50)<1, M S E=15.278$, but was significant in the cross-language condition, $F(1,50)=$ $5.59, p<.05, M S E=15.278$.

The most important result of Experiment 1 is that we obtained cross-language repetition priming in animacy decision, a conceptual implicit memory task. As we mentioned in the Introduction, several previous studies have failed to find evidence for cross-language repetition priming in lexical decision (Gerard, \& Scarborough, 1989; Kirsner, et al, 1980, 1984; Scarborough, et al., 1984). The present results are consistent with the explanation that earlier attempts to find cross-language repetition priming in the lexical decision task failed because lexical decision is not or only minimally affected by conceptual processes. Another possibility, however, is that our success in obtaining cross-language repetition priming was simply due to our stimulus materials or participants. Maybe our participants differed in their second-language fluency from those used in most other studies or maybe we happened to select stimulus materials that for one reason or another were more sensitive to cross-language repetition priming. In Experiment 2, we therefore studied cross-language repetition priming in a lexical decision task. If our success in obtaining cross-language repetition priming in Experiment 1 was due to the use of a 
conceptual implicit memory task we should find no evidence for such an effect in Experiment 2. We should, however, obtain a same-language repetition priming effect.

\section{EXPERIMENT 2}

\section{Method}

Participants. Sixty-four Dutch university students participated for a small monetary reward. Thirty-two students were assigned to the same-language repetition condition and the other 32 students were assigned to the cross-language repetition condition.

Materials and Design. The experimental stimuli were identical to those of Experiment 1. A set of 72 nonwords was constructed for the test phase. Two sets of 50 nonwords (one for the English study condition and one for the Dutch study condition) were constructed for the study phase. All nonwords were pronounceable and constructed by changing one or two letters from an existing word, either an English or a Dutch word depending on whether the nonwords were to be presented in a study block together with English or Dutch words. Nonwords were never repeated in the experiment.

Procedure. In both the study phase and the test phase, stimuli were presented in a lexical decision task. The presentation procedure was identical to that of Experiment 1. Participants made a lexical decision by pressing the /?-key for 'word' response or zkey for 'nonword' response.

The study block consisted of 96 trials and started with the presentation of 24 fillers (12 words and 12 nonwords) to familiarize participants with the lexical decision task. Subsequently, 72 stimuli were presented, consisting of the 24 experimental words, 12 word fillers and 36 nonword fillers. The study block was followed by a test block consisting of 144 trials. The test phase started with the presentation of 12 word fillers and 12 nonword fillers. Subsequently, 48 experimental words, 12 additional word fillers and 60 nonword fillers were presented. The 48 experimental words consisted of 24 new words (i.e., words that had not been presented earlier in the experiment) and 24 old words (i.e., words that had previously been presented in the study phase, either in the same language or a different language).

\section{Results and discussion}

Trimming resulted in removal of $2.6 \%$ of the reaction times. The mean reaction times and percent errors are shown in Table 2. As can be seen no cross-language repetition priming was obtained. There was, however, a same-language repetition priming effect. These conclusions were supported by two-way ANOVAs on the reaction times and error rates. The ANOVA on the mean eaction times showed that the main effect of repetition was significant, $F(1,62)=9.10, p<.01, M S E=$ 461.4. The main effect of language condition was not significant, $F(1,62)<1, M S E=5875.6$. The interaction was marginally significant, $F(1,62)=2.94, p=.09, M S E=$ 461.4. More important, simple effects showed that the repetition priming effect was significant in the samelanguage condition, $F(1,62)=11.20, p<.001, M S E=$ 461.4 , but not in the cross-language condition, $F(1,62)<$ $1, M S E=461.4$.

The ANOVA on the error rates showed that the main effect of repetition was marginally significant, $F(1,62)=$ $3.12, p<.08, M S E=15.712$. The main effect of language condition was not significant, $F(1,62)<1, M S E=26.159$. The interaction, however, was significant, $F(1,62)=7.26$, $\mathrm{p}<.01, M S E=15.712$. Simple effects showed that the repetition priming effect was significant in the samelanguage condition, $F(1,62)=9.95, p<.01, M S E=15.712$, but not in the cross-language condition, $F(1,62)<1, M S E$ $=15.712$.

To summarize, we obtained reliable same-language repetition priming but neither reaction times nor error rates showed a cross-language repetition priming effect. The absence of cross-language repetition priming in lexical decision replicates the results of several other studies (Gerard, \& Scarborough, 1989; Kirsner, et al., 1980, 1984; Scarborough, et al., 1984). Thus, the results of Experiment 1, in which we did obtain cross-language repetition priming, were not due to the selection of stimulus materials or participants that were somehow more sensitive to cross-language repetition priming than those in other studies.

Table 2

Mean Lexical Decision Times (in Milliseconds) and Percent Errors in Experiment 2

\begin{tabular}{|c|c|c|}
\hline Condition & RT & $\mathrm{PE}$ \\
\hline \multicolumn{3}{|l|}{ Same-language } \\
\hline Studied & 537 & 2.7 \\
\hline Nonstudied & 555 & 5.9 \\
\hline Priming & 18 & 3.2 \\
\hline \multicolumn{3}{|c|}{ Cross-language } \\
\hline Studied & 551 & 4.4 \\
\hline Nonstudied & 556 & 3.8 \\
\hline Priming & 5 & -0.6 \\
\hline
\end{tabular}

\section{DISCUSSION OF EXPERIMENTS 1 AND 2}

The new and interesting finding was obtained in Experiment 1 in which we obtained a reliable crosslanguage repetition priming effect in animacy decision, a conceptual implicit memory task. Experiment 2 showed that for the same stimuli cross-language repetition priming was absent in lexical decision. Together these results indicate that cross-language repetition priming is obtained in tasks that tap conceptual processing, but not in tasks that tap lexical or orthographic processing. These results are consistent with current theories of bilingual processing that assume shared conceptual 
representations, but separate lexical representations for translation equivalents. 5

\section{a) WORD ASSOCIATION MODEL}

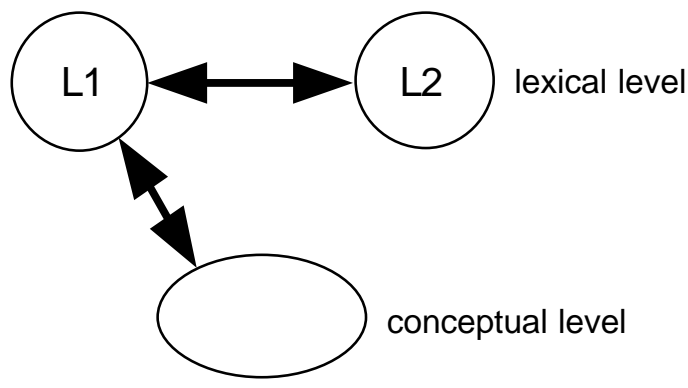

b) CONCEPT MEDIATION MODEL

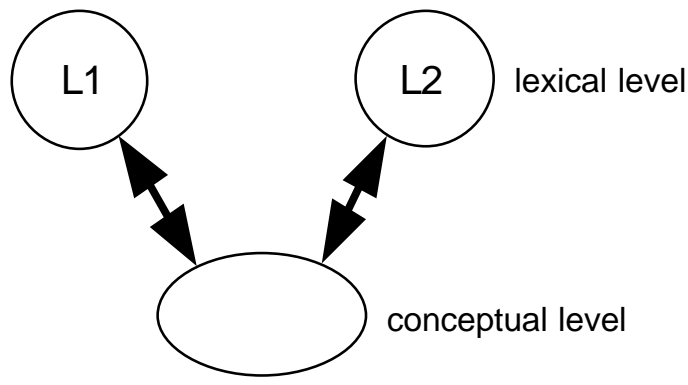

c) REVISED HIERARCHICAL MODEL

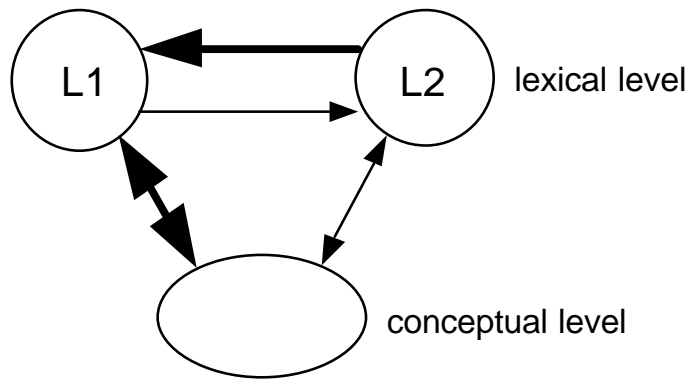

Figure 1. Alternative models of bilingual memory representation: a) word association model, b) concept mediation model, and c) revised hierarchical model. See text for details.

In Experiment 3 we investigated whether it is necessary to present words in a conceptual task during both study and test to obtain cross-language repetition priming. Words were presented in an animacy decision task during the study phase and in a lexical decision task during the test phase. Presenting a word in a conceptual task during the study phase might produce crosslanguage repetition priming in a subsequent lexical decision task if the lexical representation of the translation equivalent is accessed during study. An example of a model that makes such an assumption is the word association model (Potter, et al., 1984) shown in Figure 1a. The word association model assumes separate L1 and L2 lexical representations (where L1 refers to the native and dominant language and L2 to the second and non-dominant language) and one common conceptual representation. In the word association model there are links between the L1 and L2 lexical representations and between the L1 lexical representation and the conceptual representation. There is, however, no direct link between the L2 lexical representation and the conceptual representation. Therefore, according to the word association model, if an L2 word is presented in a task that requires access to the conceptual representation bilinguals access the conceptual representation via the L1 lexical representation. If indeed the L1 lexical representation is accessed when participants make animacy decisions to L2 words during study then a crosslanguage repetition priming effect would be expected when L1 translations equivalents are presented in a lexical decision task at test.

In contrast to the word association model, the concept mediation model (Potter et al., 1984) shown in Figure $1 \mathrm{~b}$ assumes direct links between the L2 lexical representation and the conceptual representation (and no link between the L2 and L1 lexical representations). Because the concept mediation model assumes that conceptual knowledge is accessed directly from the L2 lexical representation it predicts no cross-language repetition priming when L2 words are presented in a conceptual task at study and their L1 translation equivalents are presented in a lexical decision task at test.

A third popular model of bilingual processing is the revised hierarchical or asymmetry model proposed by Kroll and colleagues (Kroll \& Stewart, 1994; Sholl, Sankaranarayanan, \& Kroll, 1995; see de Groot, in press, and Gollan \& Kroll, 2001, for recent reviews of models of bilingual processing). This model can be viewed as an intermediate model because it assumes links between all representations (i.e., between the L2 and L1 lexical representations as well as between the L1 lexical representation and the conceptual representation and between the L2 lexical representation and the conceptual representation). However, in contrast to the concept mediation and word association models, the revised hierarchical model makes specific assumptions about the strengths of the links. In particular, the revised hierarchical model assumes that the link from the L2 lexical representation to the $\mathrm{L} 1$ lexical representation is stronger than the opposite link from the L1 lexical representation to the L2 lexical representation, as is shown in Figure 1c were thin lines represent weak links and thicker lines represent strong links. It is also assumed that the link between the $\mathrm{L} 1$ lexical representation and the conceptual representation is stronger than that between the L2 lexical representation and the conceptual representation. Because the link between the L2 lexical representation and the conceptual representation is weak the revised hierarchical model predicts that if an L2 word is presented the conceptual representation is accessed mainly via the L1 lexical representation. The revised hierarchical model therefore predicts a cross-lingual repetition priming effect in Experiment 3 in which L2 words are presented in a conceptual task at study and 
their L1 translation equivalents are presented in a lexical decision task at test.

\section{EXPERIMENT 3}

\section{Method}

Sixty-four Dutch university students participated for a small monetary reward. Thirty-two students were assigned to the same-language repetition condition and the other 32 students were assigned to the crosslanguage repetition condition.

In the study phase stimuli were presented in an animacy decision task (using the materials from Experiment 1) and in the test phase stimuli were presented in a lexical decision task (using the materials from Experiment 2). All other aspects of the materials, design and procedure were identical to those of Experiments 1 and 2.

Results and discussion

Table 3

Mean Lexical Decision Times (in Milliseconds) and Percent Errors in Experiment 3

\begin{tabular}{lrr}
\hline Condition & RT & PE \\
& & \\
\hline Same-language & 577 & 2.2 \\
$\quad$ Studied & 594 & 4.4 \\
$\quad$ Nonstudied & 17 & 2.2 \\
$\quad$ Priming & & \\
& & \\
Cross-language & 576 & 3.3 \\
$\quad$ Studied & 572 & 4.4 \\
$\quad$ Nonstudied & -4 & 1.1 \\
$\quad$ Priming & &
\end{tabular}

Note. Words were presented in an animacy decision task during the study phase.

Trimming resulted in removal of $4.8 \%$ of the reaction times. The mean reaction times and percent errors are shown in Table 3. As can be seen there was no evidence for cross-language repetition priming. We did, however, obtain a same-language repetition priming effect. These conclusions were supported by two-way ANOVAs on the reaction times and error rates. The ANOVA on the mean reaction times showed that the main effects of repetition and language condition were not significant, $F(1,62)=2.13, p>.10, M S E=547.0$ and $F(1,62)<1, M S E$ $=11730.3$, respectively. The interaction, however, was significant, $F(1,62)=6.41, p<.05, M S E=547.0$. Simple effects showed that the repetition priming effect was significant in the same-language condition, $F(1,62)=$ 7.96, $p<.01, M S E=547.0$, but not in the cross-language condition, $F(1,62)<1, M S E=547.0$.

The ANOVA on the error rates showed that the main effect of repetition was significant, $F(1,62)=7.76, p<.01$, $M S E=11.822$. The main effect of language condition and the interaction were not significant, $F(1,62)<1, M S E=$ 25.473 and $F(1,62)<1, M S E=11.822$, respectively. Simple effects showed that the repetition priming effect was significant in the same-language condition, $F(1,62)=$ $6.63, p<.05, M S E=11.822$, but not in the cross-language condition, $F(1,62)=1.86, p>.10, M S E=11.822$.

The present results show that even when words are presented in a conceptual task during study no crosslanguage repetition priming is subsequently obtained in lexical decision. Together with the results of Experiments 1 and 2 it seems fair to conclude that cross-language repetition priming is obtained only when the words are presented in a conceptual task during both study and test. These results are consistent with the idea that translation equivalents have a shared conceptual representation. Moreover, the results of Experiment 3 indicate that the shared conceptual representation can be accessed directly from the L2 lexical representation without first accessing the $\mathrm{L} 1$ lexical representation.

\section{EXPERIMENT 4}

Experiment 4 was designed to rule out an alternative explanation of our results. A critic might argue that cross-language repetition priming was present in Experiment 1, but absent in Experiments 2 and 3, because of differences in study-test lag between the experiments and not because different types of tasks were used. The number of stimuli between repetitions was larger in Experiments 2 and 3 (lexical decision) than in Experiment 1 (animacy decision). In Experiment 1, 65 stimuli intervened on average between the first and second presentation of a word (or its translation equivalent). In Experiment 2 and Experiment 3 there were on average 119 and 107 intervening stimuli, respectively. The number of intervening stimuli was larger in lexical decision because of the inclusion of nonwords. Thus, it could be argued that the absence of cross-language repetition priming in Experiments 2 and 3 was due not to the fact that a lexical decision task was used but to the longer study-test interval.

There are at least two arguments against this interpretation. First, repetition priming effects seem to be relatively insensitive to the interval between study and test. Several studies have found that repetition priming effects can be obtained even when study and test are as far as one or more days apart (e.g., Goshen-Gottstein \& Kempinsky, 2001; Jacoby \& Dallas, 1981; Scarborough, et al., 1977). Second, and maybe more important, although Experiments 2 and 3 did not show crosslanguage repetition priming they did show reliable samelanguage repetition priming. If the different crosslanguage repetition priming results in animacy decision and lexical decision were due to a difference in study-test interval one would expect a similar pattern for samelanguage repetition priming. Hence, we considered it unlikely that the reason we obtained no cross-language repetition priming in lexical decision was because we had used a longer study-test interval in this task than we had in the animacy decision task. However, to alleviate any 
remaining concerns we put this alternative explanation of our results to the test. In Experiment 4 we, therefore, studied cross-language repetition priming in a lexical decision task using a study-test interval that was somewhat shorter than that in the animacy decision task of Experiment 1. This was achieved by reducing the number of fillers. If we failed to obtain cross-language repetition priming in the lexical decision tasks of Experiments 2 and 3 because of the long study-test interval we should obtain a reliable cross-language repetition priming effect in Experiment 4 in which a shorter study-test interval was used.

\section{Method}

Thirty-four Dutch university students participated for course credit or a small monetary reward. Because the question of interest was whether we would obtain evidence for cross-language repetition priming in lexical decision with a short study-test lag only a crosslanguage condition was present in the experiment.

The procedure was similar to that of Experiment 3. The main difference was that the study-test lag was shortened by reducing the number of filler stimuli. In the study phase 48 English words were presented in an animacy decision task. The study phase started with the presentation of 24 fillers, followed by the 24 experimental words. In the test phase, 48 Dutch words and 48 nonwords were presented in a lexical decision task. The translation equivalents of 24 words had been presented in the study phase. The other 24 words had not been presented in the study phase. The average number of trials intervening between the presentation of a word in the study phase and the presentation of its translation equivalent in the test phase was 59. This was somewhat less than the average number of 65 intervening trials in Experiment 1 in which we did obtain evidence for crosslanguage repetition priming. All other aspects of the Method were identical to those of Experiment 3.

Results and discussion

\section{Table 4}

Mean Lexical Decision Times (in Milliseconds) and Percent Errors in Experiment 4

\begin{tabular}{lcc}
\hline Condition & RT & PE \\
\hline Studied & 556 & 3.9 \\
Nonstudied & 553 & 4.4 \\
Cross-language Priming & -3 & 0.5
\end{tabular}

Note. Words were presented in an animacy decision task during the study phase.

Trimming resulted in removal of $2.9 \%$ of the reaction times. The mean reaction times and percent errors are shown in Table 4. As can be seen, we again did not obtain evidence for cross-language repetition priming in lexical decision. For reaction times, as well as for error rates, $t$ tests failed to reach significance, $t(33)=0.51, p>$ .10 and $t(33)=0.49, p>.10$, respectively.

The results of Experiment 4 show that it is unlikely that the absence of cross-language repetition priming in lexical decision is due to the length of the study-test interval. Instead, a more plausible explanation is that cross-language repetition priming is obtained in tasks that require conceptual processing but not in tasks that do not require conceptual processing. So far we have obtained evidence for cross-language repetition priming in only one experiment. In Experiment 5 we wanted to extend the finding of cross-language repetition priming obtained in the animacy decision task of Experiment 1 to man-made decision, another conceptual implicit memory task that has been described in the literature (e.g., Vriezen, et al., 1995).

\section{EXPERIMENT 5}

\section{Method}

Participants. Thirty Dutch university students participated for course credit or a small monetary reward.

Materials, design and procedure. The experimental stimuli consisted of 48 English-Dutch translation pairs. Twenty-four pairs referred to man-made things (e.g., skirt-rok, spoon-lepel) and 24 pairs referred to things not man-made (mountain-berg, butterfly-vlinder). The mean cognate rating for the translation pairs was $1.35(S D=$ 0.30 ) on a scale from 1 to 7 . Frequency counts were obtained from the CELEX norms (Baayen, et al., 1993). The median frequency per million was 34.2 (range 0.6 881.0) for the Dutch words and 43.7 (range 3.7 - 400.0) for their English translation equivalents. A complete listing of the experimental stimuli is provided in the Appendix.

A set of 48 English words served as fillers in the study phase. An additional set of 24 Dutch words served as fillers in the test phase. Because the main question of interest was whether the finding of cross-language repetition priming would extend to man-made decision only a cross-language condition was present in the experiment. Two different study-test list combinations were generated for counterbalancing purposes. Across the two study-test list combinations, each word appeared once in each of the two conditions (i.e., studied vs. unstudied).

In both the study and test phase words were presented in a man-made decision task. During the study phase words were presented in English and during the test phase words were presented in Dutch. Twenty-four of the 48 critical words presented in the test phase were old (i.e., their English translation equivalent had been presented in the study phase). The other 24 words were new (i.e., their English translation equivalent had not been presented in the study phase). Twelve of the 24 old words and 12 of the 24 new words referred to man-made things and the other 12 old words and 12 new words referred to things not man-made. Participants made a manmade decision by pressing the ?/-key for 'man-made' response or the z-key for 'not man-made' response. All 
other aspects of the Method were identical to those of Experiment 1 .

\section{Results and discussion}

Trimming resulted in removal of $3.4 \%$ of the reaction times. The mean reaction times and percent errors are shown in Table 5. As can be seen we obtained crosslanguage repetition priming in man-made decision. For reaction times, as well as for error rates, $t$ tests revealed significant repetition priming effects, $t(29)=2.50, p<.05$ and $t(29)=3.56, p<.01$, respectively. Thus, the present study replicates and extends the findings of Experiment 1 in which we obtained evidence for cross-language repetition priming in animacy decision, another conceptual task.

\section{Table 5}

Mean Man-made Decision Times (in Milliseconds) and Percent Errors in Experiment 5

\begin{tabular}{lrr}
\hline Condition & RT & PE \\
\hline Studied & 722 & 7.5 \\
Nonstudied & 746 & 12.5 \\
Cross-language Priming & 24 & 5.0 \\
& & \\
\hline
\end{tabular}

\section{GENERAL DISCUSSION}

The most important findings of the present study were obtained in Experiments 1 and 5 in which we obtained evidence for long-term cross-language repetition priming in two conceptual implicit memory tasks, animacy decision and man-made decis ion. Previous studies (Gerard, \& Scarborough, 1989; Kirsner, et al., 1980, 1984; Scarborough, et al., 1984) as well as Experiments 2, 3 and 4 of the present study, failed to find evidence for cross-language repetition priming in lexical decision, a task that has been assumed to rely primarily on lexical or orthographic processing. Together these results indicate that long-term cross-language repetition priming is obtained in tasks that require access to conceptual knowledge but not in tasks in which access to conceptual knowledge is not required. The present findings lend support to current theories of bilingual memory that assume shared conceptual representations for translation equivalents.

The present study is the first to provide clear evidence for cross-language repetition priming in conceptual implicit memory tasks. Only one previously published study has investigated cross-language repetition priming in a conceptual implicit memory task. In this study Kirsner et al. (1984) failed to find evidence for cross-language repetition priming in animacy decision. It is always troublesome to pinpoint the exact reasons why two studies obtain different results, but two factors may help explain why we did obtain evidence for crosslanguage repetition priming whereas Kirsner et al. did not.
First, only 12 participants participated in the animacy decision experiment of the Kirsner et al. study and consequently the power to obtain a significant crosslanguage repetition priming effect was probably not very high. Another factor might be that in the present study words were presented in the same conceptual memory task during both study and test. Recent findings from the monolingual repetition priming literature (e.g., Vriezen et al., 1997; Huntjens, et al., 2002, Zeelenberg, Pecher, Shiffrin, \& Raaijmakers, in press) suggest that priming in conceptual implicit memory tasks depends on some rather specific aspects of a word's meaning rather than a general increase in the availability of the conceptual knowledge of a word. For example, Vriezen et al. obtained repetition priming in size decision ('Is it larger than a breadbox?') for targets that were previously also presented in size decision, but not for targets that were previously presented in man-made decision. Likewise, priming in man-made decision was obtained for targets previously presented in man-made decision, but not for targets previously presented in size decision. Vriezen et al. argued that priming is obtained only if the same type of conceptual information is accessed at study and test. In the study phase of the Kirsner et al. study participants were required to generate meaningful sentences that included the target words. Although this most likely ensured conceptual processing of the target stimuli, Kirsner et al. may have failed to find cross-language repetition priming in the subsequent animacy decision task because little or no information about animacy was stored during study.

In the present study we obtained evidence for crosslanguage repetition priming in semantic classification tasks when the words were presented in the same task during study and test. It should be noted that it is unlikely that the fact that the same decision is made at study and test is responsible for the observed priming effects (rather then whether the same conceptual knowledge is used at study and test). First, such a repeated decision explanation would also predict crosslanguage repetition priming in Experiment 2 in which words were repeated in the lexical decision task. However, no such effect was obtained. Moreover, such an explanation fails to explain a number of findings that have been reported in the monolingual repetition priming literature. Results obtained in semantic classification tasks indicate that it is not the repetition of the decision itself that is responsible for priming but rather whether or not the same type of conceptual knowledge is accessed at study and test. For example, Vriezen et al. (1995) showed that no priming in size classification ('Is it larger than a breadbox?') was obtained for words that were previously presented in man-made decision. Priming in size classification was found, however, for targets previously presented in dimension classification (Is it taller than it is wide?'). Comparable results have been reported by Huntjens et al., (2002) and Thompson-Schill and Gabrieli (1999). Also, in free association and category-exemplar production priming seems to depend on some rather specific aspects of a word's meaning. For 
example, Zeelenberg et al. (in press) studied priming in free association for target words that had been studied in sentences that emphasized certain aspects of its meaning that were more or less related to the cue that was later presented in free association. For example, in the test phase the target word BEACH was more often produced to the cue SUN if the target had been studied in the sentence 'He had a nice tan after a warm day on the $B E A C H$ ' than if it had been studied in the sentence 'Children like to play with scoops and buckets on the $B E A C H$ '. These results (see Zeelenberg, Shiffrin, \& Raaijmakers, 1999, for examples of related findings) also show that priming in conceptual tasks is highly specific and depends on the extent to which there is an the overlap in conceptual knowledge accessed at study and at test.

In the present paper we focus primarily on theories of bilingual memory, but it is worth noting that our findings are in agreement with the TAP framework of implicit memory (Blaxton, 1989; Roediger, 1990). The TAP framework predicts cross-language repetition priming only in tasks that emphasize conceptual processing, because in these tasks the processes at test recapitulate the processes at study. Durgunoglu and Roediger (1987) argued that the issue of separate vs. shared representations seems indeterminable, because whether or not cross-language transfer is obtained depends on the task that is used. Evidence for cross-language transfer is obtained in tasks that emphasize conceptual processing but not in tasks that emphasize perceptual or lexical processing. Thus, different tasks seem to provide different answers to the question whether or not translation equivalents have shared representations. Durgunoglu and Roediger argued that a more fruitful analysis of bilingual transfer is provided by a transfer appropriate processing framework in which transfer depends on the extent to which the processes at retrieval recapitulate the processes at encoding. They are probably correct that the issue of separate vs. shared representations seems indeterminable if no distinction is made between word form and word meaning. Current theories of bilingual memory, however, distinguish between a lexical and a conceptual level of representation. In our view, the TAP account is compatible with the idea that translation equivalents have separate representations at the lexical level but shared representations at the conceptual level. In fact, both accounts are very similar and predict cross-language repetition priming in tasks in which performance relies on the access of conceptual knowledge.

The finding of cross-language repetition priming is consistent with models that assume a shared conceptual representation for the two words of a translation pair. The word association model, the revised hierarchical model and the concept mediation model all make this assumption. One critical difference between these models is whether or not bilinguals have direct access to the conceptual representation from the L2 lexical representation or whether access to the conceptual representation is via the $\mathrm{L} 1$ lexical representation. The word association model (Potter, et al., 1984) as well as the revised hierarchical model (Kroll \& Stewart, 1994; Sholl, et al., 1995) assume that for L2 words the conceptual representation is accessed via the L1 lexical representation. The concept mediation model (Potter, et al., 1984) in contrast assumes that for L2 words the conceptual representation is accessed without accessing the L1 representation. The absence of cross-language repetition priming in Experiments 3 and 4 in which words were presented in animacy decision (a conceptual task) during study and in lexical decision during test indicates that participants accessed the conceptual representation directly from the L2 lexical representation and not via the L1 lexical representation. This finding is consistent with the concept mediation model.

Although there is no generally accepted way of assessing second language proficiency it is fair to say that the participants in the present study were relatively fluent Dutch-English bilinguals. An interesting question is whether similar effects will be obtained with less fluent bilinguals. Several studies (e.g., Chen \& Leung, 1989; de Groot \& Hoeks, 1995; Kroll \& Curley, 1988; Tzelgov, Henik, \& Leiser, 1990) using different experimental paradigms have shown that bilinguals with a very low level of L2 proficiency show a pattern of behavior that is consistent with the word association model, whereas more fluent bilinguals show a pattern of behavior that is consistent with the concept mediation model. Thus, it seems that as L2 proficiency increases participants tend to rely more on direct links between the L2 lexical representation and the conceptual representation and less on links between the L2 and L1 lexical representations. If a similar pattern would hold for the repetition priming paradigm one would expect to find evidence for cross-language repetition priming for less fluent bilinguals in lexical decision experiments similar to Experiments 3 and 4 of the present study. If L2 words are presented in a conceptual task during study less fluent bilinguals would access the conceptual representation via the L1 lexical representation and therefore one might expect to find a repetition priming effect if the L1 translation equivalents are subsequently presented in lexical decision. Note, however, that if during study instead of L2 words L1 words are presented in a conceptual task less fluent bilingual (as well as proficient bilinguals) would access the conceptual representation directly from the L1 lexical representation. Hence no cross-language repetition priming would be predicted for the L2 translation equivalents if they are subsequently presented in lexical decision. Future studies will have to reveal whether such a result would indeed be found.

\section{REFERENCES}

Baayen, R. H., Piepenbrock, R., \& van Rijn, H. (1993). The CELEX lexical database (CD-ROM), Linguistic Data Consortium, University of Pennsylvania, Philadelphia, PA. 
Becker, S., Moscovitch, M., Behrmann, M., \& Joordens, S. (1997). Long-term semantic priming: a computational account and empirical evidence. Journal of Experimental Psychology: Learning, Memory, and Cognition, 23, 10591082.

Blaxton, T. A. (1989). Investigating dissociations among memory measures: support for a transfer appropriate processing framework. Journal of Experimental Psychology: Learning, Memory, and Cognition, 15, 657-668.

Bowers, J. S. (2000). In defense of abstractionist theories of repetition priming and word identification. Psychonomic Bulletin \& Review, 7, 83-99.

Caramazza, A., \& Brones, I. (1980). Semantic classification by bilinguals. Canadian Journal of Psychology, 34, 77-81.

Chen, H., \& Leung, Y. (1989). Patterns of lexical processing in a nonnative language. Journal of Experimental Psychology: Learning, Memory, and Cognition, 15, 316-325.

de Groot, A. M. B. (in press). Lexical representation and lexical processing in the second language user. In Cook, V. (Ed.), Portraits of the L2 user. Clevedon, Multilingual Matters.

de Groot, A. M. B., \& Hoeks, J. C. J. (1995). The development of bilingual memory: Evidence from translation by trilinguals. Language Learning, 45, 683-724.

de Groot, A. M. B., \& Nas, G. L. J. (1991). Lexical representation of cognates and noncognates in compound bilinguals. Journal of Memory and Language, 30, 90-123.

Durgunoglu, A. Y., \& Roediger, H. L. (1987). Test differences in accessing bilingual memory. Journal of Memory and Language, 26, 377-391.

Francis, W. S. (1999). Cognitive integration of language and memory in bilinguals: semantic representation. Psychological Bulletin, 125, 193-222.

Franks, J. J., Bilbrey, C. W., Lien, K. G., \& McNamara, T. P. (2000). Transfer-appropriate processing (TAP) and repetition priming. Memory \& Cognition, 28, 1040-1051.

Forster, K. I., \& Davis. C. (1984). Repetition priming and frequency attenuation in lexical access. Journal of Experimental Psychology: Learning, Memory, and Cognition, 10, 680-689.

Gerard, L. D., \& Scarborough, D. L. (1989). Language-specific access of homographs by bilinguals. Journal of Experimental Psychology: Learning, Memory, and Cognition, 15, 305-315.

Gollan, T. H., \& Kroll, J. F. (2001). Bilingual lexical access. In B. Rapp (Ed.), The handbook of cognitive neuropsychology: What deficits reveal about the human mind (pp. 321-345). Philadelphia, PA: Psychology Press.

Goshen-Gottstein, Y., \& Kempinsky, H. (2001). Probing memory with conceptual cues at multiple retention intervals: A comparison of forgetting rates on implicit and explicit tests. Psychonomic Bulletin \& Review, 8, 139-146.

Huber, D. E., Shiffrin, R. M., Lyle, K. B., \& Ruys, K. I. (2000). Perception and preference in short-term word priming. Psychological Review, 108, 149-182.

Humphreys, M. S., Tehan, G., O'Shea, A., \& Boland, S. W. (2000). Target similarity effects: Support for the parallel distributed processing assumptions. Memory \& Cognition, 28, 798-811.

Huntjens, R. J. C., Postma, A., Hamaker, E. L., Woertman, L., van der Hart, O., \& Peters, M. (2002). Perceptual and conceptual priming in patients with dissociative disorder. Memory \& Cognition, 30, 1033-1043.

Jacoby, L. L., \& Dallas, M. (1981). On the relationship between autobiographical memory and perceptual learning. Journal of Experimental Psychology: General, 110, 306340.

Kirsner, K., Brown, H. L., Abrol, S., Chadna, N. K., \& Sharma, N. K. (1980). Bilingualism and lexical representation. Quarterly Journal of Experimental Psychology, 32, 585-594.

Kirsner, K., Smith, M. C., Lockhart, R. S., King, M. L., \& Jain, M. (1984). The bilingual lexicon: Language-specific units in an integrated network. Journal of Verbal Learning and Verbal Behavior, 23, 519-539.

Kolers, P. A. (1963). Interlingual word association. Journal of Verbal Learning and Verbal Behavior, 2, 291-300.

Kroll, J. F., \& Curley, J. (1988). Lexical memory in novice bilinguals: The role of concepts in retrieving second language words. In M. M. Gruneberg, P. E. Morris, \& R. N. Sykes (Eds.), Practical aspects of memory: Current research and issues. Vol. 2: Clinical and educational implications (pp. 389-395). Chichester; John Wiley \& Sons.

Kroll, J. F., \& Stewart, E. (1994). Category interference in translation and picture naming: Evidence for asymmetric connections between bilingual memory representations. Journal of Memory and Language, 33, 149-174.

La Heij, W., Hooglander, A., Kerling, R., \& van der Velden, E. (1996). Nonverbal context effects in forward and backward word translation: Evidence for concept mediation. Journal of Memory and Language, 35, 648-665.

MacLeod, C. M. (1991). Half a century of research on the Stroop effect: An integrative review. Psychological Bulletin, 109, 163-203.

Morris, D. C., Bransford, J. D., \& Franks, J. J. (1977). Levels of processing versus transfer appropriate processing. Journal of Verbal Learning and Verbal Behavior, 16, 519533.

Mulligan, N. W., \& Stone, M. (1999). Attention and conceptual priming: Limits on the effects of divided attention in the category-exemplar production task. Journal of Memory and Language, 41, 253-280.

Potter, M. C., So, K. F., Von Eckhart, B., \& Feldman, L. B. (1984). Lexical and conceptual representation in beginning and proficient bilinguals. Journal of Verbal Learning and Verbal Behavior, 23, 23-38.

Roediger, H. L. (1990). Implicit memory: retention without remembering. American Psychologist, 45, 1043-1056.

Roediger, H. L. (2003). Reconsidering implicit memory. In J. Bowers and C. Marsolek (Eds.), Rethinking implicit memory (pp. 8-18). Oxford University Press.

Roediger, H. L., \& Blaxton, T. A. (1987). Retrieval modes produce dissociations in memory for surface information. In D. S. Gorfein and R. R. Hoffman (Eds.), Memory and learning: The Ebbinghaus Centennial Conference (pp. 349379). Hillsdale, NJ: Erlbaum.

Roediger, H. L., \& McDermott, K. B. (1993). Implicit memory in normal human subjects. In F. Boller and J. Grafman (Eds.), Handbook of Neuropsychology, Vol. 8 (pp. 63-131). Amsterdam: Elsevier.

Scarborough, D. L., Cortese, C., \& Scarborough, H. S. (1977). Frequency and repetition effects in lexical memory. Journal 
of Experimental Psychology: Human Perception and Performance, 3, 1-17.

Scarborough, D. L., Gerard, L., \& Cortese, C. (1984). Independence of lexical access in bilingual word recognition. Journal of Verbal Learning and Verbal Behavior, 23, 84-89.

Shimamura, A. P., \& Squire, L. R. (1984). Paired-associate learning and priming in amnesia: A neuropsychological study. Journal of Experimental Psychology: General, 113, 556-570.

Sholl, A., Sankaranarayanan, A., \& Kroll, J. F. (1995). Transfer between picture naming and translation: A test of asymmetries in bilingual memory. Psychological Science, 6, 45-49.

Thompson-Schill, S. L., \& Gabrieli, J. D. E. (1999). Priming of visual and functional knowledge on a semantic classification task. Journal of Experimental Psychology: Learning, Memory, and Cognition, 25, 41-53.

Tzelgov, J., Henik, A., \& Leiser, D. (1990). Controlling Stroop interference: Evidence from a bilingual task. Journal of Experimental Psychology: Learning, Memory, \& Cognition, 16, 760-771.

van Hell, J. G., \& de Groot, A. M. B. (1998). Conceptual representation in bilingual memory: Effects of concreteness and cognate status in word association. Bilingualism: Language and Cognition, 1, 193-211.

van Heuven, W. J. B., Dijkstra, A. F. J., \& Grainger, J. (1998). Orthographic neighborhood effects in bilingual word recognition. Journal of Memory and Language, 39, 458483.

Vriezen, E. R., Moscovitch, M., \& Bellos, S. A. (1995). Priming effects in semantic classification tasks. Journal of Experimental Psychology: Learning, Memory, and Cognition, 21, 933-946.

Wagenmakers, E. M., Zeelenberg, R., Huber, D., Raaijmakers, J. G. W., Shiffrin, R. M., \& Schooler, L. J. (2003). REMI and ROUSE: Quantitative models for long-term and short-term priming in perceptual identification. In J. Bowers and C. Marsolek (Eds.), Rethinking implicit memory (pp. 105-123). Oxford University Press.

Weldon, M. S., \& Coyote, K. C. (1996). Failure to find the word picture superiority effect in implicit conceptual memory tests. Journal of Experimental Psychology: Learning, Memory, and Cognition, 22, 670-686.

Weldon, M. S. (1991). Mechanisms underlying priming on perceptual tests. Journal of Experimental Psychology: Learning, Memory, and Cognition, 17, 526-541.

Zeelenberg, R., \& Pecher. D. (2002). False memories and lexical decision: Even twelve primes do not cause long-term semantic priming. Acta Psychologica, 109, 269-284.

Zeelenberg, R., Pecher, D., Shiffrin, R. M., \& Raaijmakers, J. G. W. (in press). Semantic context effects and priming in word association. Psychonomic Bulletin \& Review.

Zeelenberg, R., Wagenmakers, E. M., \& Raaijmakers, J. G. W. (2002). Repetition priming in implicit memory tasks: Prior study causes enhanced discriminability, not only bias. Journal of Experimental Psychology: General, 131, 38-47.

Zeelenberg, R., Shiffrin, R. M., \& Raaijmakers, J. G. W. (1999). Priming in a free association task as a function of association directionality. Memory \& Cognition, 27, 956961.

\section{Author Note}

We thank Ingrid Christoffels, Judy Kroll and Hanske Roorda for insightful discussions and Yonatan Goshen-Gotstein and Henry Roediger for helpful comments on an earlier version of this paper. Correspondence concerning this article can be addressed to René Zeelenberg, Department of Psychology, Indiana University, Bloomington, IN 47405, USA. Email may be send to rzeelenb@indiana.edu.

\section{Footnotes}

1 Researchers often distinguish between short-term and longterm priming (Bowers, 2000; see Wagenmakers, Zeelenberg, Huber, Raaijmakers, Shiffrin, \& Schooler, 2003, for a discussion of recent quantitative models of short-term and long-term priming). Short-term priming refers to a paradigm in which the prime stimulus is presented immediately prior to the target stimulus (e.g., Forster \& Davis, 1984; Huber, Shiffrin, Lyle, \& Ruys, 2001). Longterm priming refers to a paradigm in which the prime and target are separated by multiple stimuli (and often several minutes or even hours). The present study is concerned with long-term priming. Hence, whenever when we discuss repetition priming in the present article we refer to the long-term repetition priming paradigm.

2 Roediger (2003) estimated that only about $10 \%$ of studies investigating implicit memory have been concerned with priming in conceptual memory tasks.

3 The finding that priming in conceptual implicit memory tasks is reduced or eliminated when different aspects of a word's meaning are emphasized at study and test, may also help explain why Kirsner et al. (1984) failed to find cross-language repetition priming in animacy decision. In the Kirsner et al. study, target words were presented in a sentence generation task during study and consequently little information about animacy may have been stored. See General Discussion for details.

4 We thank Annette de Groot and Ingrid Christoffels for providing the results of their cognate rating studies.

5 As we mentioned in the Introduction, researchers in the field of bilingual processing have attributed same-language priming in lexical decision to lexical processes. One may wonder, however, to what extent priming is due to the processing of perceptual details instead of more abstract orthographic or lexical processing. Initially, many researchers interested in longterm repetition priming focused on the distinction between perceptual and conceptual processing. Several researchers (e.g., Weldon, 1991; Bowers, 2000), however, have made finer distinctions. One question that has arisen is whether priming in visual word recognition depends on rather specific visual information or whether it depends on more abstract orthographic or lexical information. Bowers (2000) has made a strong argument for the view that priming in lexical decision is 
supported primarily by abstract orthographic codes. This position is supported by the finding that changes in case (lowercase vs. uppercase) and font from study to test typically have a minimal impact on the amount of priming. Thus, it seems that to a large extent priming in lexical decision does not depend on an exact match of the perceptual details between study and test (see Bowers, 2000, for details). 
Appendix A

Stimuli Used in Experiments 1-4

$\begin{array}{ll}\text { Dutch } & \\ \text { aap } & \text { English } \\ \text { aardappel } & \text { monkey } \\ \text { aardbei } & \text { potato } \\ \text { been } & \text { strawberry } \\ \text { bloem } & \text { flower } \\ \text { boer } & \text { farmer } \\ \text { boom } & \text { tree } \\ \text { dame } & \text { lady } \\ \text { duif } & \text { pigeon } \\ \text { eekhoorn } & \text { squirrel } \\ \text { eend } & \text { duck } \\ \text { erwt } & \text { pea } \\ \text { haai } & \text { shark } \\ \text { kikker } & \text { frog } \\ \text { konijn } & \text { rabbit } \\ \text { maag } & \text { stomach } \\ \text { mier } & \text { ant } \\ \text { paard } & \text { horse } \\ \text { schildpad } & \text { turtle } \\ \text { slager } & \text { butcher } \\ \text { staart } & \text { tail } \\ \text { varken } & \text { pig } \\ \text { verpleegster } & \text { nurse } \\ \text { vlinder } & \text { butterfly } \\ & \end{array}$

\begin{tabular}{ll}
\multicolumn{2}{c}{ Nonliving } \\
Dutch & English \\
auto & car \\
berg & mountain \\
driehoek & triangle \\
fiets & bike \\
film & movie \\
fles & bottle \\
geld & money \\
gevangenis & jail \\
handschoen & glove \\
kantoor & office \\
kogel & bullet \\
lepel & spoon \\
muur & wall \\
paraplu & umbrella \\
pijl & arrow \\
plafond & ceiling \\
raam & window \\
spiegel & mirror \\
stad & town \\
stoel & chair \\
touw & rope \\
verf & paint \\
vliegtuig & \\
wolk & cloud \\
&
\end{tabular}

Stimuli Used in Experiment 5

\begin{tabular}{ll}
\multicolumn{2}{c}{ Man-made } \\
Dutch & English \\
auto & car \\
dierentuin & zoo \\
fiets & bike \\
film & movie \\
fles & bottle \\
geld & money \\
gevangenis & jail \\
handschoen & glove \\
kerk & church \\
kogel & bullet \\
lepel & spoon \\
mes & knife \\
paraplu & umbrella \\
pijl & arrow \\
potlood & pencil \\
raam & window \\
rok & skirt \\
sleutel & key \\
spiegel & mirror \\
stoel & chair \\
touw & rope \\
verf & paint \\
vliegtuig & \\
weg & road \\
&
\end{tabular}

\section{Not Man-made}$$
\text { Dutch }
$$

English

$\begin{array}{ll}\text { aap } & \text { monkey } \\ \text { aardbei } & \text { strawberry } \\ \text { been } & \text { leg } \\ \text { berg } & \text { mountain } \\ \text { bliksem } & \text { lightning } \\ \text { bloem } & \text { flower } \\ \text { boom } & \text { tree } \\ \text { duif } & \text { pigeon } \\ \text { eend } & \text { duck } \\ \text { golf } & \text { wave } \\ \text { haai } & \text { shark } \\ \text { kikker } & \text { frog } \\ \text { konijn } & \text { rabbit } \\ \text { lucht } & \text { air } \\ \text { maag } & \text { stomach } \\ \text { mier } & \text { ant } \\ \text { paard } & \text { horse } \\ \text { schildpad } & \text { turtle } \\ \text { staart } & \text { tail } \\ \text { strand } & \text { beach } \\ \text { varken } & \text { pig } \\ \text { vlinder } & \text { butterfly } \\ & \text { woestijn } \\ \text { wolk } & \text { cloud desert }\end{array}$

